\title{
Ecosystems of the Future: Marketing and the Consumer Business Environment. Resources and the New Reality of Their Use
}

\author{
Alexey S. Kharlanov 1[ORCID 0000-0002-6427-8808], \\ Elena V. Zenkina 2[ORCID 0000-0003-2192-4715], \\ Valeriy M. Tumin $\left.{ }^{3 *[O R C I D} 0000-0003-4651-0359\right]$, \\ Petr A. Kostromin 2[ORCID 0000-0003-4161-3244], \\ Vladimir A. Trifonov 4[ORCID 0000-0003-2815-3749]
}

\author{
${ }^{1}$ Diplomatic Academy of the Ministry of Foreign Affairs of the Russian Federation, Moscow, Russia \\ ${ }^{2}$ Russian State University for the Humanities, Moscow, Russia \\ ${ }^{3}$ Moscow Polytechnic University, Moscow, Russia \\ ${ }^{4}$ Yaroslav-the-Wise Novgorod State University, Veliky Novgorod, Russia \\ vm@tumin.net
}

\begin{abstract}
The article considers the current aspects of needs satisfaction in the context of the development of two strong trends: digitalization of the process of choosing and purchasing of goods and services and the emergence of the society from the state of self-isolation during COVID-19 pandemic. The key problem of the study is the global changes in consumption ecosystems that are caused by technical, organizational and institutional factors that affect marketing, society's economic resources and the development potential of new and emerging markets of e-commerce and online sales. According to the results of the literature review, it was noted that traditional material consumption is replaced by symbolic, the satisfaction of basic needs is replaced by the need to belong to a social group or corporate brand culture, usually global and controlled by a major global transnational corporations and transnational banks. For the most part, all modern social media and business models, based on Big Data and artificial intelligence (AI) technologies, operate on the need to impose their vision of happiness on the user through the possession of a certain set of goods or services. The authors, based on the methodological apparatus of behavioral economics, highlight the irrational link in consumption, viewing it as a psychological deviation from normal economic behavior. The COVID-19 pandemic has only increased the suggestibility of focus groups and the ability to externally control them through sophisticated mechanisms of information manipulation. In this study, the authors highlighted new consumption habits and the most frequent patterns of buyer's behavior. Conclusions are drawn about the formation of new social classes due to the fact that some users live only in online, virtual world instead of the material one, and the need to introduce sustainable and moderately rational consumption. This problem is as acute as the problems of nature management and ecology, because marketing and consumerism, even if they exist only in the virtual world, are impossible without a material basis.
\end{abstract}

Keywords: COVID-19, marketing, artificial intelligence, big data, transnational corporations (TNC), consumer behavior, social intelligence

\section{INTRODUCTION}

Modern ecosystems are fixated on the rigid regulation of consumer satisfaction from the standard of walking distance (Walmart and similar chains of local saturation of customer demand) to shaping the taste and mental predilections of consumers burdened by abundant choice and 
dependent on the manipulation of market forces [1].

These forces in the period of post-pandemic recovery of global processes of the world economy are blurred and do not explicitly affect the receptors of all players of market supply and demand, indirectly and not intrusively influence the chains of represented assortments of goods and services, dissolving the distrust of each of the beneficiaries of this interaction in streams of information noise and growing shopping hunger.

Modern consumer culture has long crossed the boundaries of the material world and entered the world of symbolic goods and services (a sense of belonging), intellectual property (software codes as a material object have no value), individual products (in a single copy under the specifics of each client) $[2,3]$.

Moreover, according to E.J. Arnould and C. Thompson, modern consumption ecosystems define social interactions as a function of the consumer experience of the community, the degree of material security and market interactions [4].

M. Deuze notes that postliberalism and postmodernism have shaped symbolic consumption as well as the ability to both hide and advertise any (non-traditional, eccentric, etc.) view of life. Social media (Tik Tok, Instagram) allow one to spread one's views to a huge number of "followers". This feature is used by global companies, distributing advertising and promotional materials, often hiding their true purpose of selling something to as many customers as possible [5].

That is why M. Deuze proposes the concept of digital consumer culture as certain sets of standard online or IT-enabled consumer behaviors. In such a context, marketing interacts directly with informatics and production technology.

B.L. Dey et al. examine the evolution of the consumer experience in an era of digitalization of the economy. For example, it was concluded that there is a fundamental difference in the behavior of consumers on websites and in offline stores in the assessment of the cost of products and their qualities. And most importantly, the boundaries of online and offline worlds are being blurred in the minds and behaviors of individuals [6].

Consequently, the digital consumer culture is formed in repeated interactions between online and offline environments, the basis of which is formed by the individual consumer experience, and it relies largely on the physical experience of using a product or service [7].

W. Chong et al. note that changing standards of behavior in the digital environment have driven the emergence of a new business model of $\mathrm{O} 2 \mathrm{O}$ (onlineto-online) - practically a closed loop where demand, supply and goods are entirely generated online without moving to the physical level. In China, the market for such innovative services is growing steadily and this trend is inevitable for the whole world with its annual increase in the percentage of residents' access to Internet networks and sales of smartphones. The $\mathrm{O} 2 \mathrm{O}$ business model example shows how many industries can change: courier delivery, catering, taxis especially in interaction with classic business models: В2B, В2C, С2B и С2C [8].

W. Shiying, С. Huimiao и W. Desheng suggest that the $\mathrm{O} 2 \mathrm{O}$ model, on average, attracts more potential customers through the emergence of new online and contactless payment methods, effectively orchestrating the interaction between any potential store and any potential customer worldwide [9].

C. Chia-Chen et al. highlight a number of institutional and technical challenges hindering the development of the digital marketing ecosystem. Shops selling physical goods do not always have their own websites or sites that are understandable to users from other countries [10].

Marketing ecosystems have repeatedly been the subject of research both from the perspective of business models (Y. Ruiliang and P. Zhi [11]) and sales (S. Ruixia et al. [12]) and logistics management (C. $\mathrm{Xu}$ et al. [13]). Overall, we can conclude that consumers are multitasking and multichannel in their behavior.

For almost all companies in today's economy, customer retention issues are central to survival and competitiveness, so e-commerce may become an area where customer service levels and the number of start-ups created will eventually prove to be higher than in the real world [14].

Marketing in the digital ecosystem is facing increasing fragmentation and splitting into different sub-fields of research. L. Busca and L. Bertrandias define the goal of digital marketing as providing an integrative framework for further research, since, paradoxically, fifty years of Internet development has prevented the accumulation of knowledge in any particular marketing ecosystem, creating more and more branches and directions for further research. The authors introduce the concept of imprinting in marketing to apply and enhance cultural scripts of 
networking: mutually beneficial cooperation, joint creativity [15].

In order to successfully handle the increasing volume of marketing data, including that generated by the network, the right hardware and software tools are needed. Y.C.W. William and W. Yichuan describe Big Data as a relevant and promising tool that was originally created for technical industrial data, but quickly shifted into the field of marketing. The advantage of such systems is their ability to analyze data at the cross-organizational, crossindustry and even cross-country levels. This turns marketing, on the one hand, into an effective tool to meet personalized needs, but, on the other hand, into a tool of total consumer tracking and imposition by transnational corporations (TNCs) of their vision of an ideal consumer world and happiness through the consumption of certain mass-market products [16].

M.S. Syed et al. focus on the insufficient study of the impact of digital media on consumer behavior, both in making a purchase and in its further use [17].

\section{MATERIALS AND METHODS}

The purpose of this study was to find out how modern digital marketing in the post-pandemic era has changed consumer behavior and habits. The authors rely primarily on the works of D. Goleman [18], devoted to social intelligence, as well as the works of R.H. Thaler [19] and D. Kahneman [20] on behavioral economics.

Based on the set goal, the objectives of the study should include:

- consider the main challenges of implementing trade relations in the postpandemic era;

- describe the behavioural factors that influence the purchasing process;

- identify the reasons for the irrationality of an individual's choices.

The authors used the methodological apparatus of conducted statistical research, methods of abstractions, comparisons and analogies. The limitations of the findings may be due to changing epidemiological conditions and, consequently, the physical and mental state of the users. Behavioral economics and assumes irrational choices by the individual, external factors, rather, can only reinforce this irrationalism.

\section{RESULTS}

Modern information society is trapped not only in insufficient resources and low efficiency of their real use, but also in a trap of cytokine turbulence, where rational desire for moderate consumption is perceived by each participant of the process as a challenge to the state of permanent and increasing happiness, studied in the technologies of social intelligence, described earlier in the works of D. Goleman. At the same time the danger to perish in anatomy from such reaction of an organism to the infection or external irritants is completely blocked and extinguished in the economic ocean of the imposed behavior, the matrix of the induced external desire, which only intensifies the thirst for consumption of every individual from the position of his own uniqueness and unlimited creativity - in this case during uncontrolled shopping and allconsuming oniomania, which in Russian Christianity is called "msheloimstvo". Like any sin, oniomania is initially sweet and lullingly promising, without regard for one's own purse or the rationalities of political economy, which saw man as a rational and moderately consuming being, giving him into the arms of classical economic theory and Maslow's pyramid of needs first, and then, having proven his rigid attachment to biological and social priorities, pushing him, exhausted and under stress, into the endless bottomless barrel of rampant and unconscious consumption of the behavioral economy.

Therefore, considering the ideas of two Nobel laureates in behavioral economics R.H. Thaler and D. Kahneman, economists, producers and analysts of the global markets came to the conclusion that with the various waves of the COVID-19 pandemic the modern information-modelled consumer society was forced to reconstruct the usual format of functioning for the various tasks of the new focus groups, to consider the development and adjustment of the increasingly complex marketing concepts that define consumer behavior and form new rules for all participants in the sales chain. For this reason, the world of trade preferences has faced many new challenges: not every organization was prepared for the transition to an online format, the selflimitations, the drastic reduction in costs, the drop in profitability and network management in highly volatile markets and the highly unbalanced, sometimes highly toxic, prescriptions of dynamic $24 / 7$ trading platform operating models. This process has significantly affected the positioning of companies, their viability, market adaptability, and 
has also brought about changes in the systems of commercial relationships, namely B2C and B2B.

Since every evolutionary doubt or introduced artificial joy in the behavior of the individual becomes more and more irrational, it is necessary to consider a set of changes affecting both the trends of solvent demand itself and consumer behavior, which this article examines from two angles: psychological and economic, as a symbiosis of psychosomatic approaches and transforming relations of existing standards of relations between buyers and sellers, hunters and victims, normal and perverted individuals waiting and thirsting for violence from an initially hostile market. The hostility and volatility of these fears leads to two extremes in the state extremes of these commodity-money players: producer - to bankruptcy or to hostile takeover, and the buyer - to real starvation from an infinite number of purchased and unnecessary goods or to the bankruptcy.

COVID-19 pandemic promotes education and adaptive acquisition of new habits. Consumers are becoming increasingly involved in the digital environment. Thus, people began to spend more time in front of the computer, and accordingly, began to prefer online shopping. This has increased the effect of targeted advertising (targeting a specific target audience) shaped by user search queries. According to data provided by the Kantar Research Center, $24 \%$ of consumers have become more likely to shop online since the restrictions were introduced, and $57 \%$ are more likely to use the Internet because of COVID-19. For this reason, many companies are focusing on online pop-up ads, contextual advertising modules polarized to previous user Internet queries. Here, too, latent hooks are well applied, keeping the consumer's interest in a system of constant complicity with the processes of exchange: goods, services, information, payments, role opportunities and preferences, according to all previously stated D. Kahneman's options for including everyone in the market circulation process.

All of the 8 steps he indicated ("fear of loss", "social like", "sense of scarcity", "personal contribution to the creativity of contiguous participation in the final creation of the final product", "hard to choose" -hunger on the verge of hysteria due to limited access or resources, "anchor for the buyer", "the easier the better" and "public responsibility") add to an overcrowded and sometimes scared of death from invisible cause consciousness a chance for creativity, for individuality, for a certain recognition and prestige of the corresponding focus group, for a flight in virtual worlds to beauty, to uniqueness and to personal consistency through demand and the feedback of complicity with something beautifully wrapped and smelling delicious...

\section{DISCUSSION}

The market, as a considered ecosystem of the future and part of the business environment of the consumer, the main customer for changes in commodity-money relations, reduction of market monopolization and concentration of assets of different quality and origin, high volatility and presence of overheated "bubbles" of toxic instruments flowing between the global industries, protection against insider shake-up by TNCs and TNBs, should increasingly contribute to building a system of contractual (international, integration, national) relations of local and global checks and balances, promoting and strengthening the activities of the players themselves in the commercial infrastructure through appropriate institutionalization: market councils, 24/7 online correction of trading and operating venues, exchange and industry-specific committees, operators of trade deliveries and cargo clearance via electronic declaration, so popular today in the EAEU states, a broker-dealer network of competence assessments and analytical recommendations, training centers and a chat channel with the mega-regulator.

Under the previously proposed option of A.N. Golomzin on competition regulation, "the digital hand of the market" [21] must emerge. That is why it should be noted that the pandemic has touched practically all spheres of society, due to which it is impossible to ignore the events occurring around this subject, which cause anxiety of masses and reflections typical for a crisis, such as worries about incomes, the risk of transfer to another social group, lumpenization of behavior and lead to simplification in decision-making, at "a feast during the plague", with total unwillingness to analyze rationally and be aware of their true responsibility before themselves, family and society: "You Only Live Once" and "Two in distress make sorrow less".

This article develops the positions of contemporary authors in the field of digital marketing and the formation of a digital culture of consumption. In fact, we lay down the conceptual framework of acculturation processes by searching for factors, stakeholders and connections between them to explain the reasons for the emergence and development of a new kind of digital culture. It is 
important to note that deviant, irrational, inefficient consumption becomes the most important actor influencing the profit and other economic indicators of global corporations. We can say that this topic requires further research because of the extremely rapid changes in the digital environment, the emergence of new IT tools, goods and services in ecommerce.

\section{CONCLUSION}

The following conclusions can be drawn from the study:

1) Contemporary digital consumer culture is becoming the basis for new patterns of social interaction between members of different consumer groups who own and do not own goods considered "fashionable", indicators of social status, giving a sense of belonging to a social class.

2) The key role in the new consumer society will be played by people and groups who do not create specific products, demand for which may change not only monthly, but even daily, but who are able to organize platforms for consumer communication and exchange of experience, vision, comparison of status. Such platforms already exist: review sites, social networks for owners of specific products or brand adherents. Digital gamification trends are expected to gradually take over all aspects of the digital and physical world, where shopping will become like a game of "treasure hunting" at a greater scale than other people. The task of behavioral economics in this context is to find a balance between super profits of TNCs due to irrational behavior of people and obtaining personalized benefits for the needs of a particular user.

3) The development of the modern consumer ecosystem, by and large, erases the boundaries of outdated social classes, but is also actively shaping new ones. Anonymity of communication and shopping online, the ability to create an infinite number of accounts erase the boundaries of gender, ethnicity, religion, age, geographic location and many other traditional signs of classification.

Digital consumption in unlimited quantities is creating new virtual social classes, the interaction within which will be based on common habits, interests, and the choice of one brand or trademark.
And it is not a fact that it will be the consumers' personal choice. Already in the example of modern advertising, we see that celebrities, and now rather bloggers (sometimes these people are the same individuals) are the leaders of the public choice, leading the audience and telling them which product is better and which is not. In fact, it will mean the destruction of the singular physical self in favor of avatars, groups, and the development of the concept of the aggregate self as a set of cultural patterns of behavior programmed by corporations.

Any major social disruption (and the coronavirus pandemic is certainly one of them) means a breakdown of existing business and social patterns of behaviour. That is, they wear themselves out, become ineffective and even dangerous to others. Irresponsible and unrestrained consumption will lead to the collapse of modern civilization, according to numerous forecasts, by the year 2100. The main goal of today's digital marketing ecosystem is to ensure sustainable and rational consumption, both in terms of people's psyche and available and accessible material resources. Regardless of the extent to which the digital world has penetrated our lives and purchases, it is not possible without real tangible production. This simple idea is often not even considered when planning development programs for the digital economy, management and other areas of modern life, although it is fundamental in organizing the interaction between marketing tools, available resources and the potential of economic objects.

\section{AUTHORS' CONTRIBUTIONS}

The article was written by a team of 5 authors. Alexey S. Kharlanov analyzed modern consumer habits in the post-pandemic era and the psychological aspects of online shopping behavior. Elena V. Zenkina highlighted key digital marketing trends in shaping the ecosystem potential of the future economy. Valeriy M. Tumin and Vladimir A. Trifonov described the place and role of TNCs and TNBs in determining the necessary list of goods and services considered as the mandatory minimum and unattainable maximum for members of modern society. Petr A. Kostromin conducted a literature review of approaches to $\mathrm{O} 2 \mathrm{O}$ business models in the digital age and consumer behavior in the online environment.

\section{REFERENCES}

[1] O.Y. Myasnikova, I.I. Shatalova, E.V. Zenkina, T.V. Bogacheva, N.I. Illeritsky, G.M. Kutlyeva, 
"Promising directions of cooperation among Eurasian Economic Union countries", International Journal of Engineering and Technology (UAE), 2018, vol. 7(3.14), pp. 386391. DOI: 10.14419/ijet.v7i3.6.16009

[2] B.L. Dey, D. Yen, S. Lalnunpuia "Digital consumer culture and digital acculturation", International Journal of Information Management, 2020, vol. 51. DOI: 10.1016/j.ijinfomgt.2019.102057

[3] L.S. Valinurova, E.A. Sulimova, T.G. Guseva, E.A. Bolotina, V.M. Tumin, "Post-crisis modeling of economic development trends in an on-going recession of national economies", Montenegrin Journal of Economicsthis, 2021, vol. $17(2)$, pp. 75-82. DOI: $10.14254 / 1800$ $5845 / 2021.17-2.6$

[4] E.J. Arnould, C. Thompson, "Consumer culture theory: Twenty years of research", The Journal of Consumer Research, 2005, vol. 31(4), pp. 868-882. DOI: $10.1086 / 426626$

[5] M. Deuze, "Participation, remediation, bricolage: Considering principal components of a digital culture", The Information Society, 2006, vol. 22(2), pp. 63-75. DOI: 10.1080/01972240600567170

[6] B.L. Dey, M.M. Babu, M. Rahman, M. Dora, N. Mishra, "Technology upgrading through cocreation of value in developing societies: Analysis of the mobile telephone industry in Bangladesh", Technological Forecasting and Social Change, 2018, vol. 145, pp. 413-425. DOI: 10.1016/j.techfore.2018.05.011

[7] M. Rahman, S. Bose, M.M. Babu, B.L. Dey, S.K. Roy, B. Ben, "Value Cocreationas a dialectical process: Study in Bangladesh", Information Systems Frontiers, 2019, vol. 21(3), pp. 527-545. DOI: 10.1007/s10796-019-09902-4

[8] W. Chong, W. Yanqing, W. Jixiao, X. Jiuling, L. Jian, "Factors influencing consumers' purchase decision-making in $\mathrm{O} 2 \mathrm{O}$ business model: Evidence from consumers' overall evaluation", Journal of Retailing and Consumer Services, 2021, vol. 61. DOI: 10.1016/j.jretconser.2021.102565

[9] W. Shiying, C. Huimiao, W. Desheng, "Regulating platform competition in two-sided markets under the $\mathrm{O} 2 \mathrm{O}$ era", International Journal of Production Economics, 2019, vol. 215, pp. 131-143. DOI: 10.1016/j.ijpe.2017.10.031
[10]C. Chia-Chen, H. Kuo-Lun, H. Cheng-Han, "Understanding usage transfer behavior of two way O2O services", Computers in Human Behavior, 2019, vol. 100, pp. 184-191. DOI: 10.1016/j.chb.2018.07.009

[11]Y. Ruiliang, P. Zhi, "Return policies and $\mathrm{O} 2 \mathrm{O}$ coordination in the e-tailing age", Journal of Retailing and Consumer Services, 2019, vol. 50, pp. 314-321.

DOI: 10.1016/j.jretconser.2018.07.006

[12] S. Ruixia, C. Hongyu, P.S. Suresh, "A generalized count model on customers' purchases in O2O market", International Journal of Production Economics, 2019, vol. 215, pp. 121-130. DOI: 10.1016/j.ijpe.2017.11.009

[13] C. Xu, W. Xiaojun, J. Xinkuang, "The impact of power structure on the retail service supply chain with an $\mathrm{O} 2 \mathrm{O}$ mixed channel", Journal of the Operational Research Society, 2016, vol. 67(2), pp. 294-301. DOI: 10.1057/jors.2015.6

[14]S. Chien-wen, C. Min, W. Chiao-Chen, "Analyzing the trend of $\mathrm{O} 2 \mathrm{O}$ commerce by bilingual text mining on social media", Computers in Human Behavior, 2019, vol. 101, pp. 474-483. DOI: 10.1016/j.chb.2018.09.031

[15] L. Busca, L. Bertrandias, "A Framework for Digital Marketing Research: Investigating the Four Cultural Eras of Digital Marketing", Journal of Interactive Marketing, 2020, vol. 49, pp. 1-19. DOI: 10.1016/j.intmar.2019.08.002

[16] Y.C.W. William, W. Yichuan, "Analytics in the era of big data: The digital transformations and value creation in industrial marketing", Industrial Marketing Management, 2020, vol. 86, pp. 12-15. DOI: 10.1016/j.indmarman.2020.01.005

[17]M.S. Syed, B.L. Dey, M.M. Kamal, S.F.S. Alwi, "Consumer engagement with social media platforms: A study of the influence of attitudinal components on cutting edge technology adaptation behavior", Computers in Human Behavior, 2021, vol. 121. DOI: 10.1016/j.chb.2021.106802

[18]D. Goleman, "A Force for Good: The Dalai Lama's Vision for Our World", Bantam, First Edition, 2015.

[19]R.H. Thaler, "Misbehaving: The Making of Behavioral Economics", New York: W.W. Norton \& Company, 2015.

[20] D. Kahneman, O. Sibony, C.R. Sunstein, "Noise: 
A Flaw in Human Judgment", San Francisco: William Collins Little, Brown Spark, 2021.

[21]A.N. Golomzin, "About competition and regulation. Theory, history, practice, prospects", M.: RG-Press LLC, 2020, 21 p. (In Russ.). 